\title{
A trial to allow motorcycles on bus lanes in Tel-Aviv: an assessment of mobility and safety impacts
}

\author{
VICTORIA GITELMAN, ROBY CARMEL, ANNA KORCHATOV
}

Transportation Research Institute, Technion City, Haifa, Israel 32000

KEYWORDS: Bus lanes; motorcycles; behavior; safety; mobility

ABSTRACT: While motorcycles or powered two-wheelers (PTWs) provide mobility benefits in dense urban areas, their riders are exposed to a high risk of injury. Bus lane use by PTWs is suggested in international practice as a measure for improving PTW safety and mobility although examinations of its impacts are rare, with results reported mostly in the United Kingdom. Based on the literature, it was anticipated that the measure would increase the use of bus lanes by PTWs and keeping to their travel lanes, thus improving PTW mobility and reducing conflicts with other vehicles. However, concerns were raised regarding possible disturbances to bus traffic while the safety impacts of the measure are unclear. In Israel, a trial on the use of bus lanes by PTWs was introduced in Tel-Aviv, on two major traffic routes, and was accompanied by an evaluation study. The study aimed to examine the mobility and safety impacts of the measure, by comparing PTW behaviors and accident numbers, during the trial as opposed to the before period. The study observations were collected by means of video-recordings on road sections, traffic cameras at junctions, and mobile cameras attached to helmets in a group of PTW volunteers. The findings showed that during the trial, the rate of PTWs using bus lanes increased by $4-5 \%$ when traffic was flowing, and by $6-8 \%$ when traffic was congested, but PTWs continued to be observed on other traffic lanes. When travelling through a road segment, most PTWs kept to their lane, but a consistent change in this behavior was not found. During the trial, the amount and severity of conflicts between PTWs and other vehicles did not increase, and the passing times of buses and PTWs along the routes did not change. Mixed trends were observed in both total and PTW-involved accidents, with no significant change. Overall, allowing PTWs on the bus lanes in Tel-Aviv resulted in slight improvements in PTW mobility, without impairing bus travel times or road safety. The absence of substantial behavior changes during the trial indicated that the new measure actually "regulated" the situation that was previously present in traffic.

\section{INTRODUCTION}

Motorcycles or powered two-wheelers (PTWs) constitute an important part in transportation systems of many countries (Haworth, 2012; IMMA, 2014; ITF, 2015). Motorcycles are a personal travel mode, providing mobility freedom and flexibility in densely populated areas. They are able to weave through traffic congestion by passing between vehicles, make it easier to find a parking space close to destination and have lower fuel consumption and travel costs relative to private cars (Van Eslande and Elvik, 2012). In recent decades, an increasing use of motorcycles of various kinds has been observed, throughout the world, mostly in metropolitan areas (Rogers, 2008; Haworth, 2012). According to an IMMA report (2014), in many developing countries motorcycle share exceeds $40 \%$, while in some developed countries, such as USA and Australia, motorcycle use is reaching 10\%. A recent report indicated (Breene, 2018) that the popularity of PTWs in Europe continues, while the PTW stock increased by $34 \%$ since 2000. Similarly, in Israel, the PTW fleet increased by $70 \%$ between 2003 and 2016 (CBS, 2017). The reasons behind the prominent increase in motorcycle use vary among countries, depending on the purpose of use as well as on economic, demographic, social and cultural factors, such as fuel costs, congestion level, policy changes and life styles (Haworth, 2012; Rogers, 2008).

However, beside mobility benefits, PTWs belong to the most vulnerable road users, along with pedestrians and cyclists, due to the high risk of injury in road accidents. Motorcycle riders are unprotected in collisions with motor vehicles or road infrastructure and are sensitive to external disturbances, e.g. poor roadway conditions (Keall and Newstead, 2012; Van Eslande and Elvik, 2012). Moreover, due to their small size, high maneuverability, acceleration capabilities and the use of these features in traffic (e.g. filtering), PTWs are frequently not foreseen by other vehicles. As a result, motorcycle riders are exposed to higher and more severe injury risk than car occupants (Vlahogianni et al., 2012; ITF, 2015). Statistical data from developed countries show consistently that the share of PTW riders among road traffic fatalities is several times higher than the PTW share in the national vehicle fleet (Van Eslande and Elvik, 2012; ITF, 2015). In Israel, in 2018, PTW riders accounted for $14 \%$ of total fatalities and for $25 \%$ of serious injuries, while the PTW share in the vehicle fleet was $4 \%$ only and in vehicle-kilometers travelled - less than 2\% (CBS, 2019; RSA, 2019).

Recognizing the increasing use of PTWs throughout the world and their benefits for urban mobility, the need for measures to address their high level of risk is emphasized in many sources (Van Eslande and Elvik, 2012; IMMA, 2014; ITF, 2015; Breene, 2018). Previous research suggested various countermeasures which may contribute to improving PTW users' safety, among those: infrastructure changes, technology solutions in PTWs and other vehicles, wearing helmets and protective clothing by PTW riders, training and enforcement of safer riding, publicity for road sharing, etc. (Haworth, 2012; 2-Be-Safe, 2012; ITF, 2015; Araujo et al., 2017).

One of the measures for improving motorcycle safety in urban areas is seen in allowing the use of bus lanes by PTWs. A European project reported (2-Be-Safe, 2012) that this measure is implemented in a number of European cities, for example, in London, Stockholm, Vienna, and Barcelona.

\subsection{Previous research on the use of bus lanes by PTWs}

During rush hours, PTWs tend to weave between lanes and even move into oncoming lanes to bypass stalled traffic. Such 
behavior gives rise to various dangers, e.g. colliding with an opening car door, conflict with the oncoming traffic, or hitting a pedestrian seeking to cross (IHE, 2015). Allowing PTWs on bus lanes is thought to prevent such dangers as the PTWs are not forced to crowd within lanes shared with other vehicles, thereby reducing conflicts and accident risks (2-Be-Safe, 2012). Similarly, it is assumed that PTWs using bus lanes will not interfere with bus traffic because they can clear the road by moving into adjacent lanes when necessary. On the other hand, concerns were raised that PTWs in bus lanes may exacerbate safety problems as the result of increased conflicts between buses and PTWs, and that adding PTWs to the bus lane will interfere with bus travel times. Nonetheless, according to assessments conducted in European trials, permitting PTWs in bus lanes usually did not cause a deterioration in safety or any considerable change to bus travel (2-Be-Safe, 2012).

In the United Kingdom, a series of studies were conducted to examine the effect of PTW use of bus lanes. For example, the Transport for London Authority report (TfL, 2004) summarized the trial results for allowing PTWs to use three bus lanes in London. The pilot was conducted over a two-year period and the research found that during the trial there was a decrease in total and PTW-involving accidents, the number of PTWs increased substantially in the bus lanes and decreased in other traffic lanes, while bus travel speed increased after the change.

Subsequent research by TfL (2008) performed a broader assessment of the above measure's effect over a period of 36 months and applying several methods to examine accident changes. They found that the measure was associated with safety improvement according to most evaluations of accidents involving PTWs, but the results were not statistically significant. Furthermore, the TfL (2008) report presented a summary of previous trials conducted in the United Kingdom in which PTWs were permitted on bus routes, including:

- A trial on the M4 in London in which a decrease in total accidents and accidents involving PTWs was observed;

- A trial carried out in three London districts, there, following permission for PTWs to use bus lanes, a decline was observed in accidents with vulnerable road users, namely, PTWs, pedestrians, and bicycles;

- A trial carried out in Bristol, on $16 \mathrm{kms}$ of bus lanes, in which no accidents involving PTWs, pedestrians or bicycle riders were reported during the first six months of the measure's implementation, and a decline in PTW accidents was observed for the duration of the trial period.

York et al. (2008) examined changes in traffic and safety following permission for PTWs travel in bus lanes in the Westminster City area in London. A "before-after" evaluation was carried out at selected sites, with features that could increase the chance for conflicts between various road users, e.g. bus stops, junction areas. A wide range of data was collected including: traffic counts with vehicle composition; video-recordings of PTW behaviors; recording bus and PTW license plates at the entrance and exit points to estimate travel times; accident counts. The study found that during the "after" period: the percentage of PTW use of bus lanes doubled; most PTWs kept to their lane; the number of conflicts between PTWs, buses, and pedestrians declined; travel times for buses slightly increased; and the number of accidents did not change and even decreased.

In January 2009, PTWs were allowed to travel in most of the bus lanes in Metropolitan London. York et al. (2010), examined implications of the measure during the first 10 months of its implementation, by considering: use of bus lanes by different vehicles; travel times of buses and PTWs; conflicts in bus lanes; and road accidents. Most traffic and behavioral data were collected by video-cameras, where two static cameras were placed at the entrance and exit of each site. The study found that: the share of PTWs using bus lanes rose from $0-35 \%$ (with an average of 6\%), in the "before" period, to $27-80 \%$ (with an average of $51 \%$ ), in the "after" period; the amount of PTW traffic in bus lanes rose by $4 \%$; the conflict rate declined from $3 \%$ to $1 \%$, although most were at a low severity level, thus, having no practical implications on safety. However, an increase in PTW accidents was observed. Therefore, when continuing the trial in London, the target speed for PTWs was set at $30 \mathrm{mph}$, and accompanied by police enforcement and a publicity campaign.

In a consequent study by York et al. (2011), additional safety evaluations were carried out, both at the road network where the measure was implemented and at the groups of sites with various enforcement levels. They found that PTW accident rates on sections with bus lanes did not change compared to control sites. The study concluded that the PTW accident rate on sections allowing PTW travel in bus lanes was not different than that of other routes in Metropolitan London (York et al., 2011). Following both evaluations (York et al, 2010; 2011), the London Department of Transportation announced permission for PTW travel in most bus lanes (IHE, 2015).

The 2-Be-Safe (2012) study reported on a pilot use of the measure in a number of bus lanes in Vienna, which was found to be successful, with no increase in collisions between buses and PTWs. Among the benefits of the measure, the study pointed to improvements in PTW mobility without disturbing other road users and preventing PTW filtering between vehicle lines, thus reducing the risk for collisions between PTWs and other vehicles.

In general, the European 2-Be-Safe (2012) study presented PTW travelling in bus lanes as a measure for mainly improving PTW mobility, while the European eSUM (2012) research project, based on the results of British studies, stated that PTW use of bus lanes may improve PTW safety. According to 2-Be-Safe (2012), PTW use of bus lanes is appropriate for application in urban areas and can be efficient in countries with a high degree of compliance with the law. Following permission for PTWs to travel in bus lanes, a rise in the number of PTWs travelling in bus lanes and a decrease in PTW travel time can be expected, while PTW presence in bus lanes is not supposed to influence bus travel times (2-Be-Safe, 2012). However, care must be taken to ensure that there is no worsening in the number of accidents involving PTWs after the measure's application.

\subsection{The Israeli study}

Previous research showed that with the increasing density of urban traffic and raising awareness of the need for improved PTW mobility and safety, more cities around the world are considering the possibility of permitting PTW travel in bus lanes. While this measure has been introduced in a number of countries, the detailed examinations of its impacts are not common and have been reported mostly in the United Kingdom.

In Israel, following a decision by the Ministry of Transport and the Tel-Aviv-Yafo Municipality, the use of bus lanes by PTWs was introduced in the city of Tel-Aviv, in the form of a trial on two major traffic routes, with a total length of $5.5 \mathrm{~km}$ (Figure 1-a). The measure was initiated in the middle of February 2016. The public was informed of the change through the media and new traffic signs installed on the roadsides showing that PTWs had permission to use the bus lanes. The trial was planned for half a year and was accompanied by an evaluation study, with a supervising committee which included representatives of the Ministry of Transport, 


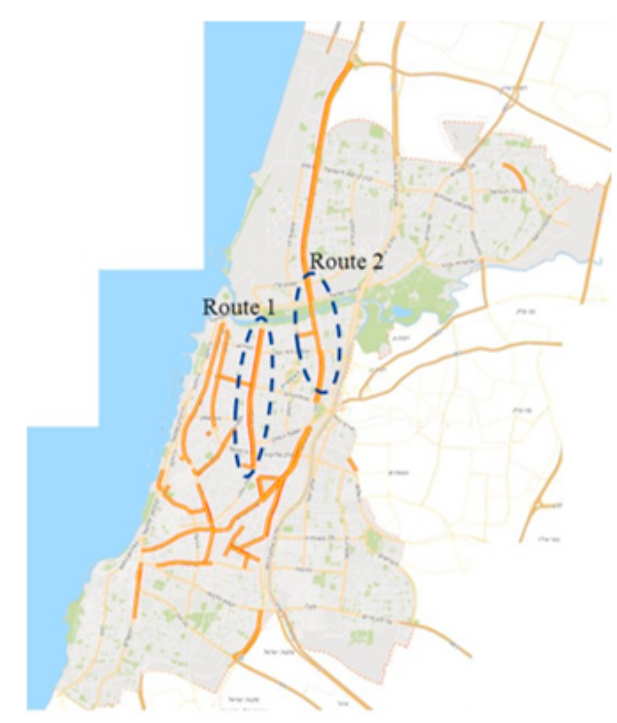

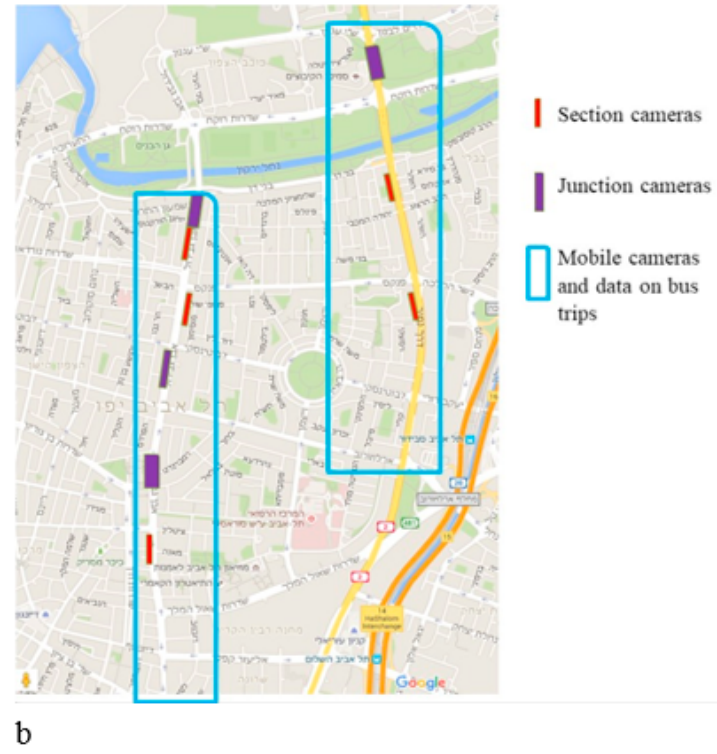

$\mathrm{b}$

Figure 1. Study routes on Tel-Aviv-Yafo map (a); locations of means for behavior data collection on the study routes (b).

the city, bus operators and the police. The study aimed to examine the mobility and safety impacts of the measure, by comparing road user behavior indicators and accident changes, on the two routes, before and after implementation of the measure.

The main contribution of this study to the existing literature can be seen in the detailed examination of changes in PTW behaviors, travel conditions and the safety level of the streets following the introduction of the measure. Research on the topic is rare in the international literature, except for the studies conducted in the UK, which also varied in scope. Furthermore, related to previous research, the study extended the examinations of PTW interactions with other road users on the bus lanes and, particularly, when a PTW appears behind the bus which stopped at a bus stop - the topic that was not considered in the past.

\section{METHODOLOGY}

\subsection{The study framework}

The study included two urban routes with bus lanes, Ibn Gvirol Street (Route 1), and Namir Road (Route 2) (see Fig.1-a). Both streets are divided roads with a built median, curbside bus lanes, and two to three lanes of general traffic in each direction. The bus lanes were operated in the morning and evening hours on Route 1 and on the northern part of Route 2, and for the entire day on the central part of Route 2 .

The study applied an after-before design, where behavior and accident indicators are estimated and compared at the study sites, in the after period when the measure was implemented, with the same indicators in the before period. Based on the international experience (York et al., 2008; 2010; 2011; 2-Be-Safe, 2012; IHE, 2015), the shared use of bus lanes by PTWs was expected to increase the use of bus lanes by PTWs and keeping to their travel lanes by PTWs, to reduce conflicts between PTWs and other vehicles, and to improve PTW mobility. Furthermore, it was not anticipated to have a detrimental impact on the travel times of buses or safety levels in the streets involved. All these impacts were to be examined in the study based on field observations of traffic and road user behaviors and on the analysis of accident changes, during the trial as opposed to the before period. Thus, to estimate the implications of the measure, under the local conditions, the following behaviors were monitored:
- The use of bus lanes and of adjacent traffic lanes, by PTWs; - PTW behaviors while travelling on the street sections: keeping in lane by PTWs; PTW filtering between standing vehicles under traffic congestion; conflict occurrences between PTWs and other road users;

- PTW and bus travel times on the study streets.

In addition, accident rates on the study routes were compared between the trial and the previous time periods.

\subsection{Data collection and analyses}

\subsubsection{Behavior data}

Field measurements and observations of road user behaviors were carried out during two periods: before allowing PTWs to travel in bus lanes, in the first two weeks of February, 2016, and after implementing the measure, in May-June of that year ${ }^{1}$. The data were collected using a number of means: (1) video-cameras on street sections; (2) video-cameras at intersections; (3) mobile video-cameras on PTW riders and (4) data on bus trip times from a bus operating company. In particular:

(1) Fixed video-cameras were placed, for the study purposes, on five sections of the trial routes (herein: "section cameras"). At each site, two video-cameras were installed at a distance of about $150 \mathrm{~m}$ from each other which recorded the activities on the bus lanes and adjacent lanes for seven to ten hours, per each round of observations. (This method of data collection followed York et al., 2008; 2010). At each site, the section cameras were used to produce: (a) Traffic data - traffic volume and composition, in each lane; (b) PTW behaviors while travelling on the street sections; (c) Behavioral data on the bus lanes; (d) PTW behaviors when those are observed behind buses stopped near bus stops (if relevant); (e) Identification of PTWs and buses at section entrances and exits for estimating travel times.

(2) Video-cameras of the Tel-Aviv Municipality control center provided data at four intersections on the trial streets (herein: "junction cameras"). These camera-records were added to enrich the study data. At each intersection, the videorecords were collected during a weekday for the duration of

1 All data were collected in dry and sunny days, without rain. The average temperature in Tel-Aviv in February is $14^{\circ} \mathrm{C}$, in May-June is $21^{\circ}-23^{\circ} \mathrm{C}$. Both conditions are comfortable for PTW travels, thus a strong weather effect between the periods was not expected. 
eight hours, per each round of observations. At each site, the junction cameras were used to produce traffic and behavior data of types $a$ - $d$ as indicated above for section cameras, with an extension "before and after the intersection" as in most cases the junction camera could cover the whole road width (both traffic directions of either side of the median). This means that two data samples could be provided per junction, separately for each travel direction.

(3) Mobile video-cameras were attached to helmets of the PTW riders - a group of volunteers from the bike-club who collaborated with the study (herein: "mobile cameras"). The riders switched on the cameras when they travelled on the study routes, during weekdays in the hours of bus lane operation. These video-films were used for estimating PTW passing times through the study routes. Likewise, the films were applied for documenting PTW behaviors while travelling over the trial sections, e.g. the use of bus lanes, lane changes while travelling, conflict occurrence with other road users.

(4) Data on bus trip times on the study streets were derived from a geographic information system of the "Dan" bus company (which operates bus lines in the Tel-Aviv metropolitan area). The data was collected for a set of bus lines running on both routes, in both travel directions, during the hours of bus lane operation. The same set of the bus lines was controlled for in each round of observations.

Figure 1-b presents an overview of the locations of means applied for behavior data collection in the study.

The video footage was decrypted manually, by the research team, using pre-defined forms and rules. A member of the research team decrypted the same sites during both study periods. Details on data preparation are provided below regarding the use of section camera films.

As indicated above, two cameras were fixed on each section, when one camera recorded traffic at mid-section (the main film) and another camera was placed at the end of the section (a complementary film). The main film served for collecting traffic and behavioral data at the site and identifying PTWs and buses at the section entry. The second film was used for repeat identification of PTWs and buses, for estimating passing times. For decryption, the main footage was marked by two aerial lines, and the complementary footage by one aerial line. For example, Figure 2 -a shows aerial lines marked on the films from Site 2, to define the follow-up window. Line 1 in the main film served to count vehicles and identify PTWs and buses entering the section for estimating passing times and for selecting PTWs and buses to document their behaviors ("beginning of follow-up window"). Line 2 in this film marks the boundary of the area for behavioral documentation ("end of follow-up window"). Line 3 in the second film marks the line for identifying PTWs and buses exiting the section (for estimating passing times).

The following rules were used for documenting traffic and behaviors on the study sections:

- Traffic counts were made for each traffic lane according to seven vehicle types. The counts were performed over quarter-hour periods, in each half-hour of observations. The values were aggregated for hourly approximations. Each site received average values of traffic volume and traffic composition, in each lane.

- PTW behaviors during segment travel were documented for the first 15 PTWs during each half-hour of observations. For each PTW, the following data were documented: traffic conditions on the road section when the PTW appeared (flowing, slow or congestion); PTW location at the beginning of follow-up window (bus lane, nearby or another lane); whether the PTW changed lanes while travelling (no, yes once, yes more than once); whether the PTW used bus lane while travelling (no, yes partially, yes fully); in congestion - whether the PTW filtered between standing vehicles (yes, no); whether a conflict was observed between the PTW and another vehicle or the PTW and a pedestrian. In addition, separate samples were collected to monitor behaviors on the bus lanes. For that, for the first ten buses which appeared on the bus lane during each half-hour of observations were recorded: traffic conditions; whether the bus changed the lane and whether a conflict was observed between the bus and another vehicle (or PTW).

A conflict was defined as a change in speed (braking) and/ or direction of moving by the actors in order to avoid a collision. This definition is common in observational studies of road user interactions (Ewing and Dumbaugh, 2009). Concerning PTW conflicts with other traffic participants, in this study we adopted the approach applied by York et al. (2008; 2010), where four conflict levels were defined: level 1 - regular braking/not abrupt change of direction ("precaution"); level 2 - hard braking or abrupt change of direction, under low speed ("under control"); level 3 - like level 2 but under high speed ("near-miss"), level 4 - a collision. Conflicts at levels 1 and 2 actually reflect interactions between the PTW and another vehicle or pedestrian, without creating dangerous situations.

- Separate attention in the study was given to PTW behaviors when a PTW appears behind the bus which stopped at a bus stop. The literature on the shared use of bus lanes by PTWs did not discuss this topic but the issue was raised by the bus operators involved in the trial. They indicated that a situation where a PTW appears behind a bus stopping at the bus stop could be dangerous because of the bus driver's limited field of view which restricts the driver from being able to see the PTW behind the bus, while permitting PTWs to travel on the bus lanes could increase that risk. For a focused examination of this issue, specific data samples were collected. Using the film, for each bus that stopped at the bus stop the time of its arrival and departure was documented, and for each case when a PTW appeared on the bus lane behind the bus that stopped, were recorded: the time of PTW appearance; the state of road traffic; what the PTW did - changed the lane and continued moving or waited until the bus returned to move on the bus lane; whether a conflict occurred between the PTW and another vehicle (with four conflict levels as defined above). The data were applied for the examination of both the frequency of instances when a PTW appears behind a stopped bus and the risk level in such situations.

- Passing times of PTWs and buses were calculated as differences between the time of crossing of aerial line 1 and line 3, at each site. Such data was collected for the first five PTWs and buses during each half-hour.

A similar approach was applied for data preparation using junction camera films. Video-cameras of the traffic control center were available for four intersections along the study routes, of which three were on Route 1 and one on Route 2. At three intersections, it was possible to watch both travel directions, oncoming the junction and moving away. For each travel direction at the intersection, two aerial lines were drawn on the films for documenting PTW behaviors while travelling along the segment and bus behaviors on the bus lanes. Figure 2-b presents, for example, the aerial lines marked on the films of 777 intersection on Route 1, for both travel directions. Road user behaviors were documented during their travel between lines 1 and 2, and lines 3 and 4, respectively. Using junction camera films, traffic counts, data samples of PTW behaviors, samples to monitor behaviors on the bus lanes and samples to characterize PTW behav- 


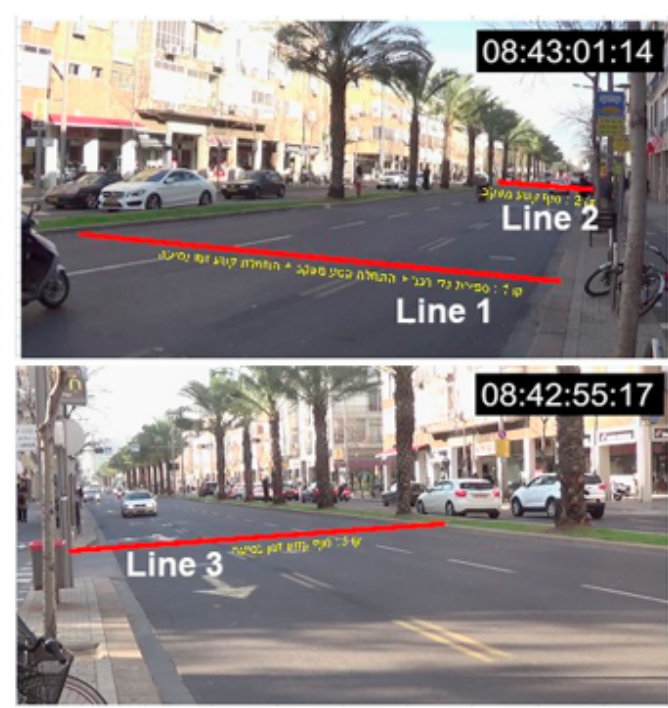

a

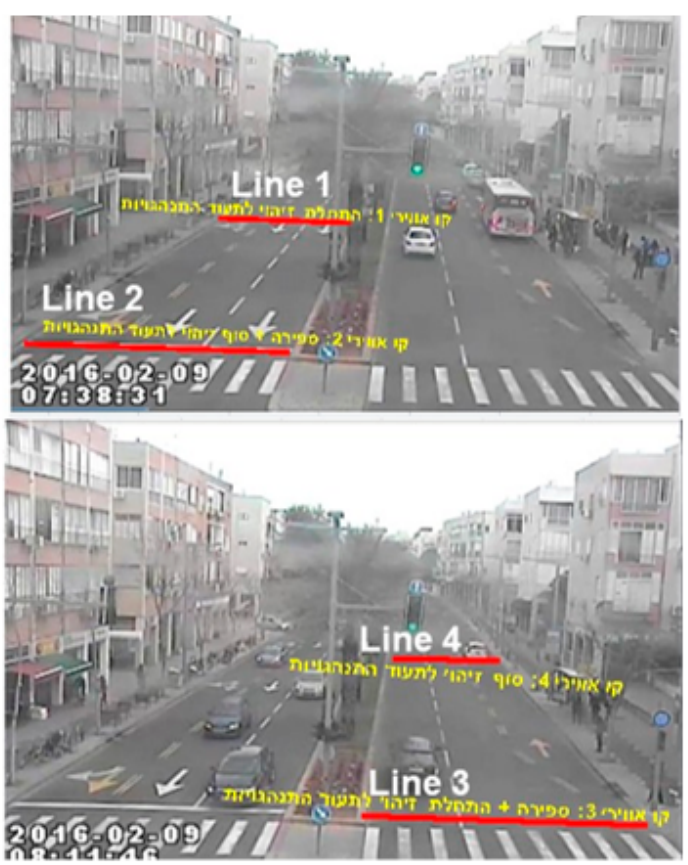

$\mathrm{b}$

Figure 2. Examples of definitions of follow-up windows for data preparation: a - on section camera films (Site 2), b - on junction camera films (J77).

iors behind the buses which stopped at the bus stops were prepared, following the rules described above for the use of section camera films.

Traffic and behavior indicators were estimated as a percentage of certain feature out of the sample collected, at each study site, in both periods of observations; for travel times, average values were obtained. The indicators based on traffic counts were estimated separately for morning and evening-afternoon hours of bus lane operation, while other indicators used the whole data samples. The significance of differences between the behavior indicators in the period after the measure's initiation versus the before period was examined using a $\mathrm{z}$-test for proportions and a t-test for average values (Jekel et al., 2007). The difference was judged as significant with $\mathrm{p}<0.05$.

\subsubsection{Accident data}

Road accident changes were examined during the trial period in comparison to previous years, with regard to total injury accidents, severe accidents and accidents involving buses and PTWs. Accident data for both routes were extracted from the national accident files. The analysis compared monthly accident rates on road sections and intersections, on both study routes, in the after versus before period; the "after" period was defined from February through August, 2016 (seven months) and the "before" period from January, 2014 through January, 2016 (25 months). The significance of differences in accident rates was estimated using a T-statistic as described in Griffith (1999). Due to the short after period and relatively low accident counts on the study sites, the accident analysis was preliminary in nature and applied a simple after-before comparison of accident rates.

\section{RESULTS}

\subsection{Use of bus lanes and other lanes by motorcycles}

Table 1 presents a summary of the shares of PTWs in the traffic volume, for each lane in the study sections, before and after implementing the new measure (based on the data from section cameras). One can observe that after implementing the new measure, PTWs constituted $14-26 \%$ of the vehicles observed in the bus lanes on Route 1, and $5-14 \%$ on Route 2. Nonetheless, PTWs were observed in lanes adjacent to the bus lanes. For example, in nearby lanes, at sites of Route 1, between $6-15 \%$ of the vehicles were PTWs, and $4-7 \%$ at sites of Route 2. This means that the share of PTWs travelling in adjacent lanes was lower than in the bus lanes. However, PTW usage of adjacent lanes did not cease following implementation of the new measure. In the after period, the PTW presence in the bus lanes increased at most of the sites relative to the before period; at some sites, the change was significant and indicated an additional 5-6\% of PTWs on the bus lanes. On average for all the sites, the share of PTWs on the bus lanes rose from $11 \%$ to $14 \%(\mathrm{p}<0.01)$. The rise in bus lane usage by PTWs, under the new conditions, was in accordance with expectations ${ }^{2}$.

At the same time, the share of PTWs in traffic in the after period also rose in adjacent lanes. This finding is contrary to expectations based on the findings from the international literature, as allowing PTW travel on the bus lanes was supposed to reduce PTW travel in other lanes. Examining the total traffic volume and its composition during the after period in comparison to the before one (see Table 1-b) revealed that, although the total volume and the share of buses in traffic did not change, the number of PTWs passing through the study streets did increase, so that their share in the total traffic rose from $6 \%$ to $7 \%$. The increase in total number of PTWs in traffic, in the after period, could possibly explain the lack of decline in PTW presence in adjacent lanes.

Table 2 shows the shares of PTWs in the traffic volume, in each lane, in both study periods based on the data from junction cameras. The findings indicate that in the after period, the share of PTWs on the bus lanes was $12-25 \%$ on Route 1 , and $8-10 \%$ on Route 2 (except for one site, J81, in morning hours, where the presence of PTWs was abnormally low). In the after period, the share of PTWs observed on the bus lanes rose at all sites compared to the before period, with the exception of Site J81; in some cases, the increase was

2 Beside buses and PTWs, other vehicles used the bus lanes, such as: taxis ( $40 \%$ in the before and $39 \%$ in the after period), private/commercial vehicles ( $24 \%$ and $21 \%$, respectively), and bicycles ( $3 \%$ and $4 \%$ ). 


\begin{tabular}{|c|c|c|c|c|c|c|c|c|c|c|c|c|c|}
\hline \multicolumn{2}{|c|}{ a - At separate sites } & \multicolumn{2}{|c|}{ Before: Bus lane } & \multicolumn{2}{|c|}{ Nearby lane } & \multicolumn{2}{|c|}{ Far lane } & \multicolumn{2}{|c|}{ After: Bus lane } & \multicolumn{2}{|c|}{ Nearby lane } & \multicolumn{2}{|c|}{ Far lane } \\
\hline Site & Hours & $\mathrm{N}$ & PTWs (\%) & $\mathrm{N}$ & PTWs (\%) & $\mathrm{N}$ & PTWs (\%) & $\mathrm{N}$ & PTWs (\%) & $\mathrm{N}$ & PTWs (\%) & $\mathrm{N}$ & PTWs (\%) \\
\hline \multirow[t]{2}{*}{1} & morning & 134 & 11.9 & 669 & 5.1 & 635 & 2.2 & 156 & 18.6 & 674 & 6.1 & 642 & 1.9 \\
\hline & evening & 165 & 20.6 & 628 & 5.9 & 545 & 3.1 & 61 & 26.2 & 697 & $8.3^{*}$ & 652 & 4.6 \\
\hline \multirow[t]{2}{*}{2} & morning & 346 & 17.1 & 573 & 6.5 & 536 & 3.7 & 356 & $22.8^{*}$ & 548 & 6.6 & 509 & 3.1 \\
\hline & evening & 279 & 19.4 & 745 & 6.7 & 640 & 5.3 & 289 & 23.5 & 812 & $9.4^{*}$ & 682 & 5.6 \\
\hline \multirow[t]{2}{*}{3} & morning & 137 & 20.4 & 569 & 7.9 & 436 & 5.5 & 123 & 18.7 & 608 & 7.6 & 467 & 6.2 \\
\hline & evening & 134 & 12.7 & 511 & 12.3 & 389 & 10.5 & 98 & 14.3 & 584 & 15.4 & 432 & 11.1 \\
\hline \multirow[t]{2}{*}{4} & morning & 419 & 8.8 & 700 & 2.9 & 730 & 2.7 & 363 & $13.8^{* *}$ & 578 & 3.6 & 596 & 3.0 \\
\hline & evening & 295 & 5.1 & 728 & 4.1 & 736 & 3.4 & 339 & 5.0 & 723 & 4.6 & 778 & 4.0 \\
\hline \multirow[t]{2}{*}{5} & morning & 366 & 5.5 & 890 & 4.5 & 872 & 3.3 & 294 & 6.8 & 715 & 4.1 & 677 & 2.2 \\
\hline & evening & 435 & 5.3 & 633 & 6.2 & 588 & 2.7 & 368 & 6.0 & 677 & 6.8 & 651 & 2.8 \\
\hline
\end{tabular}

\begin{tabular}{|c|c|c|c|c|c|c|c|c|c|c|}
\hline \multirow[t]{2}{*}{ b - A total for study sites } & \multicolumn{3}{|c|}{ Bus lanes } & \multicolumn{2}{|c|}{ Nearby lanes } & \multicolumn{2}{|c|}{ Far lanes } & \multicolumn{3}{|c|}{ All lanes" } \\
\hline & $\mathrm{N}^{\wedge}$ & buses (\%) & PTWs (\%) & $\mathrm{N}^{\wedge}$ & PTWs (\%) & $\mathrm{N}^{\wedge}$ & PTWs (\%) & $\mathrm{N}^{\wedge}$ & buses (\%) & PTWs (\%) \\
\hline Before & 2710 & $21 \%$ & $11 \%$ & 6646 & $6 \%$ & 6107 & $4 \%$ & 16746 & $5 \%$ & $6 \%$ \\
\hline After & 2447 & $22 \%$ & $14 \%{ }^{* *}$ & 6616 & $7 \% *$ & 6086 & $4 \%$ & 16230 & $5 \%$ & $7 \%^{* * *}$ \\
\hline
\end{tabular}

Notes: Sites 1-3 on Route 1; Sites 4-5 on Route 2. Morning hours between 7-10 (at Site 2 btw 8-10), evening - afternoon-evening hours between 14-19. $\mathrm{N}$ - Average hourly traffic volume. ${ }^{* *} \mathrm{p}<0.01,{ }^{* *} \mathrm{p}<0.05,{ }^{*} \mathrm{p}<0.1$ in after-before comparisons. "Including bus lanes and $2-3$ lanes for general traffic. ^A sum of average hourly traffic volumes.

Table 1. Shares of PTWs out of the hourly traffic counts on bus lanes and other lanes, in before and after periods (section cameras).

\begin{tabular}{|c|c|c|c|c|c|c|c|c|c|}
\hline \multirow[b]{2}{*}{ Site - junction } & \multirow[b]{2}{*}{ Hours } & \multicolumn{2}{|c|}{ Before: Bus lane } & \multicolumn{2}{|c|}{ Nearby lane } & \multicolumn{2}{|c|}{ After: Bus lane } & \multicolumn{2}{|c|}{ Nearby lane } \\
\hline & & $\mathrm{N}$ & PTWs (\%) & $\mathrm{N}$ & PTWs (\%) & $\mathrm{N}$ & PTWs (\%) & $\mathrm{N}$ & PTWs (\%) \\
\hline \multirow[t]{2}{*}{$\mathrm{J} 151 \operatorname{dir} 1$} & morning & 201 & 6.0 & 547 & 3.8 & 158 & 10.1 & 490 & 3.7 \\
\hline & evening & 363 & 7.4 & 802 & 1.8 & 374 & 10.2 & 805 & 2.2 \\
\hline \multirow[t]{2}{*}{$J 151 \operatorname{dir} 2$} & morning & 518 & 7.5 & 852 & 3.9 & 482 & 7.9 & 887 & 3.7 \\
\hline & evening & 405 & 6.2 & 828 & 4.0 & 558 & $9.7^{\star *}$ & 729 & 4.9 \\
\hline \multirow[t]{2}{*}{ J77 dir1 } & morning & 209 & 8.1 & 560 & 4.1 & 220 & 12.7 & 567 & 4.9 \\
\hline & evening & 329 & 7.9 & 518 & 5.8 & 295 & $13.6^{* *}$ & 636 & $8.3^{*}$ \\
\hline \multirow[t]{2}{*}{ J77 dir 2} & morning & 88 & 9.1 & 657 & 6.5 & 76 & $18.4^{*}$ & 631 & 8.4 \\
\hline & evening & 95 & 14.7 & 714 & 4.9 & 146 & 17.8 & 750 & 6.5 \\
\hline \multirow[t]{2}{*}{ J79 dir2 } & morning & 199 & 11.6 & 709 & 8.2 & 212 & $18.4^{*}$ & 693 & 7.5 \\
\hline & evening & 184 & 17.4 & 661 & 7.4 & 165 & $25.5^{*}$ & 760 & $10.3^{*}$ \\
\hline \multirow[t]{2}{*}{ J81 dir 1} & morning & 358 & 15.4 & 507 & 6.7 & 363 & 12.4 & 469 & 6.8 \\
\hline & evening & 345 & 15.1 & 400 & 8.8 & 342 & 12.9 & 478 & 9.2 \\
\hline \multirow[t]{2}{*}{ J81 dir 2} & morning & 90 & 13.3 & 455 & 7.7 & 67 & $4.5^{\star}$ & 401 & 10.0 \\
\hline & evening & 133 & 21.8 & 638 & 9.3 & 113 & 17.7 & 627 & $12.8^{* *}$ \\
\hline
\end{tabular}

Notes: Junction J151 on Route 2, other junctions on Route 1. Travel directions according to camera views: dir1 - before the junction (entering traffic), dir2 - after the junction (moving away traffic). Morning hours between 7-10, evening - afternoon-evening hours between 14-19.

$\mathrm{N}$ - Average hourly traffic volume. "* $\mathrm{p}<0.05,{ }^{*} \mathrm{p}<0.1$ in after-before comparisons.

Table 2. Shares of PTWs out of the hourly traffic counts on bus lanes and nearby lanes, in before and after periods (junction cameras).

significant (see Table 2). As an average among all the sites in this group, the share of PTWs on the bus lanes increased from $10.5 \%$ to $12.5 \%$, between the two periods (a significant change, $\mathrm{p}<0.01$ ). However, in the after period, PTWs were still observed in other traffic lanes. In general, the findings from the analysis of junction camera data were similar to those from section cameras (as presented above), i.e. showing an increased use of bus lanes by PTWs under the new conditions but together with a continued presence of PTWs in other lanes, whereas the latter appears to be associated with a growth in the PTW volume in the after period.

Table 3 provides a summary of traffic conditions during PTW travel on the study sections and PTWs' use of bus lanes, based on the PTW samples produced from section cameras. In many cases, in both periods, the PTWs travelled in flowing or slow traffic conditions, while congestion cases were observed rarely, mostly at Site 1, and the proportion of congested traffic declined in the after period. In the after period, at the line of PTW appearance on the section (the "beginning of followup window", as explained in Sec .2), 38-39\% of PTWs were observed on the bus lanes at Sites 1-2, and $22-24 \%$ at Sites 4-5. The extent of bus lane use by PTWs was lower at Site 3 (a similar finding can be seen in Table 1). Comparing the two periods, the changes in the shares of PTWs observed on the bus lanes while entrancing a section, were not significant.

In the after period, during travel on a section under flowing or slow traffic conditions, at most of the sites, between $24-60 \%$ of the PTWs used the bus lanes (see Table 3). In addition, in the after period relative to before, a significant increase of the bus lane use by PTWs was observed at Sites 2 and 4 . In contrast, at Site 3, a decline in the bus lane use by PTWs was observed in the after period. While travelling on 
a section under traffic congestion, most PTWs used the bus lanes; at Site 1, a significant increase in the share of PTWs using the bus lane was observed in the after compared to the before period. In general, in the after period, there was a rise in bus lane use by PTWs. As an average between the study sites, an increase of $4 \%$ was obtained in the bus lane use by PTWs under flowing or slow traffic conditions, and of $6 \%$ in congestion, although, the changes were not uniform among the sites.

Similarly, based on the PTW samples from junction cameras (Table 4), most PTWs were observed in flowing or slow traffic conditions, while congestion was observed mainly at two intersections (J77 and J81, in one travel direction); the proportion of congested conditions near intersections increased in the after period. On travel segments near intersections, in the after period, at the line of PTW appearance (the "beginning of follow-up window"), 32-35\% of PTWs were observed in the bus lanes on Route $2,17-40 \%$ on Route 1 in the southern direction, and $7-16 \%$ on the same route in the northern direction. Compared to the before period, at most sites, an increase in the share of PTWs using the bus lanes was observed, which was significant at two sites. On average among all the sites, the share of PTWs observed on the bus lanes (while entering the segment) rose by $3.8 \%$.

Under flowing or slow traffic conditions near intersections, most PTWs did not travel on the bus lanes. In the after period compared to before, at all sites except for one (J81 in the northern direction), an increase was observed in the bus lane use by PTWs, which was significant in some cases. As an average estimate for all sites (in Table 4), the share of PTWs travelling on the bus lanes under flowing or slow traffic condi- tions, rose by $4.7 \%$. Under congestion, the majority of PTWs near intersections travelled on the bus lanes; for example, $54-77 \%$ in the after period. In the after period compared to before, an increase in the share of PTWs using bus lanes was observed, which was significant in a number of cases (see Table 4). On average, the share of PTWs travelling on the bus lanes in congestion rose by $8 \%$.

It can be noted that according to the data of mobile-cameras which were attached to the PTW riders passing through the study routes, the use of bus lanes by PTWs also increased in the after period. However, PTWs did not cease travelling in other lanes and used various lanes for their trips depending on traffic situations along the routes.

\subsection{Other PTW behaviors: keeping in lane, filtering, conflict occurrence}

Other PTW behaviors that can be influenced by the measure are: keeping in lane by PTW while travelling on a road section; PTW filtering between vehicles under traffic congestion; and conflict occurrence between PTWs and other road users. Table 5 presents findings regarding these issues based on section cameras' data. One can see that under flowing or slow traffic conditions, in keeping traffic lanes by PTWs, inconsistent changes were observed in the after compared to before period: a significant increase in the percent of PTWs who changed the lane at Sites 2 and 4, a significant decrease at Sites 3 and 5, and no change at Site 1 . At the same time, under congestion, in the after period compared to before, at Site 1, fewer PTWs changed lanes or filtered between standing vehicles to move ahead $(\mathrm{p}<0.05)$; at other sites, the samples of PTWs observed under congestion were minor.

\begin{tabular}{|c|c|c|c|c|c|c|c|c|c|c|c|c|c|c|c|c|}
\hline \multirow[t]{2}{*}{$\underset{\vec{t}}{\tilde{F}}$} & \multirow[t]{2}{*}{ 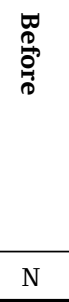 } & \multicolumn{3}{|c|}{ 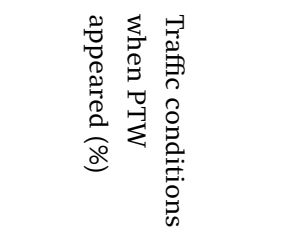 } & \multirow[t]{2}{*}{ 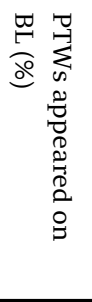 } & \multirow[t]{2}{*}{ 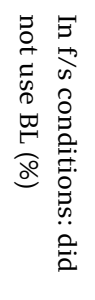 } & \multicolumn{2}{|c|}{ 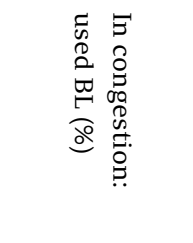 } & \multirow[t]{2}{*}{$\underset{\overparen{D}}{\mathbb{9}}$} & \multicolumn{3}{|c|}{ 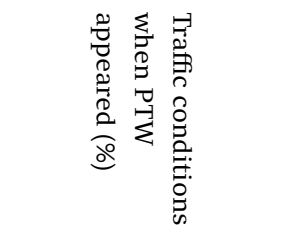 } & \multirow[t]{2}{*}{ 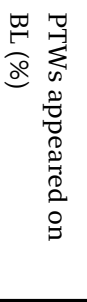 } & \multirow[t]{2}{*}{ 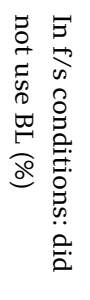 } & \multicolumn{2}{|c|}{ 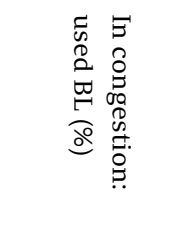 } \\
\hline & & $\mathrm{f}$ & $\mathrm{s}$ & c & & & partly & fully & & $\mathrm{f}$ & $\mathrm{s}$ & c & & & partly & fully \\
\hline 1 & 314 & 33.1 & 36.0 & 30.9 & 35.4 & 55.8 & 35.1 & 34.0 & 195 & $48.7^{\#}$ & $22.6^{\#}$ & 28.7 & 39.0 & 58.3 & $16.1^{\#}$ & $64.3^{\#}$ \\
\hline 2 & 249 & 71.5 & 19.3 & 9.2 & 34.1 & 49.6 & 43.5 & 47.8 & 180 & $80.6^{\prime \prime}$ & $11.7^{\#}$ & 7.8 & 37.8 & $39.8^{\star}$ & 57.1 & 35.7 \\
\hline 3 & 445 & 90.3 & 7.9 & 1.8 & 9.0 & 80.8 & 25.0 & 62.5 & 228 & $96.9^{*}$ & $1.8^{\#}$ & 1.3 & 11.4 & $86.2^{\star}$ & -- & -- \\
\hline 4 & 240 & 80.0 & 10.0 & 10.0 & 25.8 & 74.1 & 12.5 & 75.0 & 247 & $44.9^{\#}$ & $54.7^{\#}$ & $0.4^{\#}$ & 24.3 & $57.3^{\#}$ & -- & -- \\
\hline 5 & 240 & 82.5 & 10.8 & 6.7 & 24.6 & 74.6 & 12.5 & 62.5 & 239 & $95.0^{*}$ & $2.9^{*}$ & $2.1^{\#}$ & 21.8 & 75.6 & -- & -- \\
\hline
\end{tabular}

Notes: $f$ - flowing, $s$ - slow, $c$ - congestion. $B L$ - bus lane. $\mathrm{N}$ - sample of PTWs. ${ }^{*} \mathrm{p}<0.05$, ${ }^{\mathrm{p}} \mathrm{p}<0.1$ in after-before comparisons. -- minor samples (below 10 ).

Table 3. Use of bus lanes by PTWs (section cameras).

\begin{tabular}{|c|c|c|c|c|c|c|c|c|c|c|c|c|}
\hline \multirow[t]{2}{*}{ 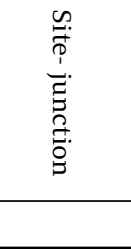 } & \multirow[t]{2}{*}{$\begin{array}{l}\text { ष्ण } \\
\stackrel{0}{0} \\
\stackrel{0}{0} \\
\mathrm{~N}\end{array}$} & \multirow[t]{2}{*}{ 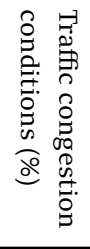 } & \multirow[t]{2}{*}{ 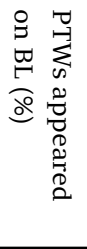 } & \multirow[t]{2}{*}{ 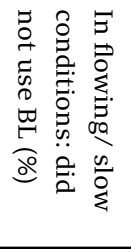 } & \multicolumn{2}{|c|}{ 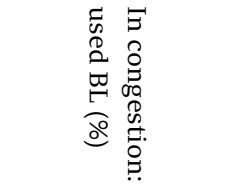 } & \multirow[t]{2}{*}{ 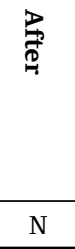 } & \multirow[t]{2}{*}{ 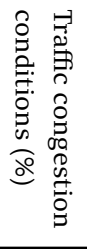 } & \multirow[t]{2}{*}{ 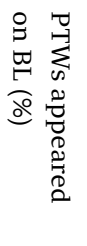 } & \multirow[t]{2}{*}{ 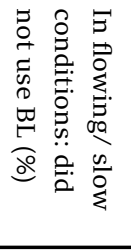 } & \multicolumn{2}{|c|}{ 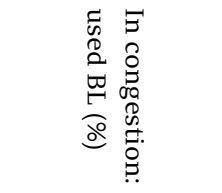 } \\
\hline & & & & & partly & fully & & & & & partly & fully \\
\hline J151 dir1 & 654 & 0 & 26.3 & 65.6 & - & - & 239 & $10.5^{\#}$ & $35.1^{\#}$ & 61.2 & 32.0 & 40.0 \\
\hline J151 dir 2 & 832 & 4.0 & 26.9 & 67.1 & 21.2 & 54.6 & 240 & $9.2^{\#}$ & 32.1 & 63.3 & 36.4 & 40.9 \\
\hline J77 dir1 & 240 & 38.8 & 33.8 & 55.8 & 30.1 & 24.7 & 224 & 33.5 & 39.7 & 47 & $42.7^{\circ}$ & 17.3 \\
\hline J77 dir2 & 493 & 0 & 11.4 & 85.2 & - & - & 225 & 0 & 15.6 & $73.3^{*}$ & - & - \\
\hline J79 dir 2 & 240 & 0 & 20.4 & 79.2 & - & - & 240 & 0 & 17.5 & 76.7 & - & - \\
\hline J81 dir1 & 210 & 31.4 & 22.4 & 63.9 & 31.8 & 4.5 & 210 & $56.7^{\#}$ & $31.4^{\#}$ & 54.9 & 39.5 & $14.3^{\#}$ \\
\hline J81 dir2 & 401 & 1.5 & 11.2 & 83.8 & 16.7 & 0 & 208 & 0 & 7.2 & $90.9^{\#}$ & - & - \\
\hline
\end{tabular}

Notes: $\mathrm{N}$ - sample of PTWs. $B L$ - bus lane. " $\mathrm{p}<0.05,{ }^{\mathrm{p}} \mathrm{p}<0.1$ in after-before comparisons. -- minor samples (below 10).

Table 4. Use of bus lanes by PTWs (junction cameras). 


\begin{tabular}{|c|c|c|c|c|c|c|c|c|c|c|c|c|c|c|}
\hline \multirow[b]{2}{*}{ 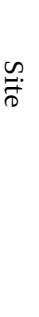 } & \multicolumn{3}{|c|}{ Before: In f/s conditions } & \multicolumn{4}{|c|}{ Before: In congestion } & \multicolumn{3}{|c|}{ After: In f/s conditions } & \multicolumn{4}{|c|}{ After: In congestion } \\
\hline & $z$ & 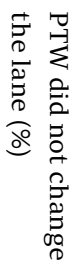 & 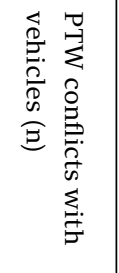 & z & 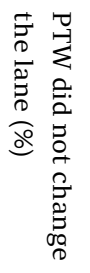 & 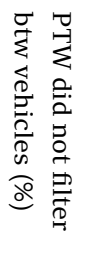 & 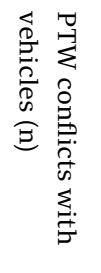 & z & 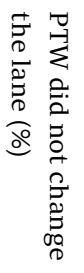 & 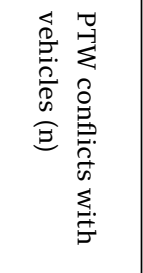 & z & 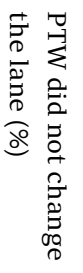 & 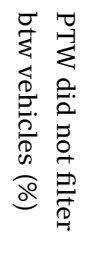 & 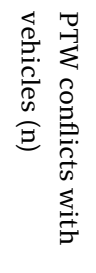 \\
\hline 1 & 217 & 77.4 & 0 & 97 & 54.6 & 8.3 & 0 & 139 & 73.4 & 0 & 56 & $75.0^{\circ}$ & $64.3^{*}$ & 0 \\
\hline 2 & 226 & 65.9 & $3(1 / 2)^{*}$ & 23 & 60.9 & 52.2 & $1(0 / 1)$ & 166 & $42.2^{\circ}$ & $5(5 / 0)$ & 14 & 28.6 & 28.6 & $1(1 / 0)$ \\
\hline 3 & 437 & 74.6 & $4(0 / 4)$ & 8 & -- & -- & 0 & 225 & $88.0^{\circ}$ & 0 & 3 & -- & -- & 0 \\
\hline 4 & 216 & 88.0 & 0 & 24 & 83.3 & 33.3 & 0 & 246 & $44.3^{*}$ & $11^{*}(11 / 0)$ & 1 & -- & -- & 0 \\
\hline 5 & 224 & 89.3 & 0 & 16 & 81.3 & 87.5 & 0 & 234 & $94.9^{*}$ & 0 & 5 & -- & -- & 0 \\
\hline
\end{tabular}

Notes: $f / s$ - flowing/slow. $\mathrm{N}$ - a sample of PTWs. "p $<0.05$ in after-before comparisons. -- minor samples (below 10$).{ }^{*}(\mathrm{x} / \mathrm{y})$ indicates the number of level 1 and level 2 conflicts.

Table 5. PTW behaviors: keeping in lane while moving on a road section, filtering and conflict occurrences (section cameras).

\begin{tabular}{|c|c|c|c|c|c|c|c|c|c|c|c|c|c|c|}
\hline \multirow[b]{2}{*}{ 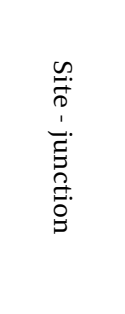 } & \multicolumn{4}{|c|}{ Before: In $\mathrm{f} / \mathrm{s}$ conditions } & \multicolumn{3}{|c|}{ Before: In congestion ${ }^{\&}$} & \multicolumn{4}{|c|}{ After: In f/s conditions } & \multicolumn{3}{|c|}{ After: In congestion ${ }^{\otimes}$} \\
\hline & $z$ & 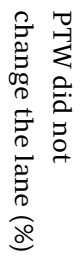 & 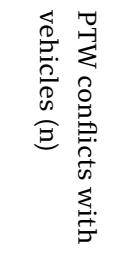 & 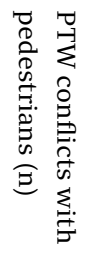 & $z$ & 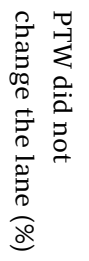 & 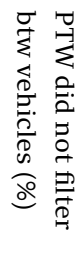 & $z$ & 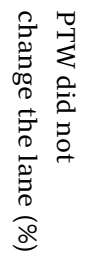 & 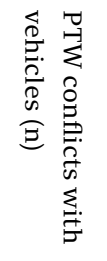 & 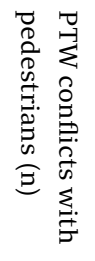 & $z$ & 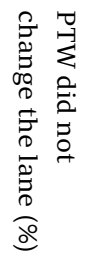 & 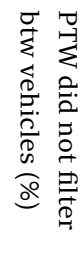 \\
\hline J151 dir1 & 654 & 75.8 & $2(2 / 0)^{*}$ & 0 & -- & -- & -- & 214 & 81.8 & 0 & 0 & 25 & 64.0 & 72.0 \\
\hline J151 dir2 & 799 & 63.1 & $10(10 / 0)$ & 0 & 33 & 66.7 & 6.1 & 218 & 67.4 & 0 & $1^{\wedge}$ & 22 & 54.5 & 22.7 \\
\hline $\mathrm{J} 77 \operatorname{dir} 1$ & 147 & 79.6 & 0 & 0 & 93 & 54.8 & 33.3 & 149 & $61.1^{*}$ & 0 & 0 & 75 & $36.0^{*}$ & 26.7 \\
\hline J77 dir2 & 493 & 75.3 & $3(2 / 1)$ & 0 & -- & -- & -- & 225 & 76.4 & $1(1 / 0)$ & 0 & -- & -- & -- \\
\hline J79 dir2 & 240 & 64.6 & 0 & $1(1 / 0)$ & -- & -- & -- & 240 & 66.3 & 0 & 0 & -- & -- & -- \\
\hline J81 dir1 & 144 & 49.3 & $2(2 / 0)$ & 0 & 66 & 25.8 & 4.5 & 91 & $62.6^{*}$ & 0 & 0 & 119 & $52.1^{*}$ & 29.4 \\
\hline J81 dir2 & 395 & 69.1 & $1(1 / 0)$ & 0 & 6 & 66.7 & 50.0 & 208 & $83.2^{*}$ & $1(0 / 1)$ & 0 & -- & -- & -- \\
\hline
\end{tabular}

Notes: $f / s$ - flowing/slow. $\mathrm{N}$ - a sample of PTWs. "p<0.05 in after-before comparisons. -- not observed. " $(\mathrm{x} / \mathrm{y})$ indicates the number of level 1 and level 2 conflicts. ${ }^{\circledR}$ no conflicts observed. ^ a conflict of level 3.

Table 6. PTW behaviors: keeping in lane while moving near intersection, filtering and conflict occurrences (junction cameras).

Both before and after implementing the new measure, conflict occurrences between PTWs and other vehicles were rare (see Table 5). Comparing the after and before periods, an increase in the extent of conflicts at Site 4 was observed, from 0 to $4.5 \%$. However, in the after period, all the events were of level 1 ("precaution"), which actually reflects the interactions between various road users, without real danger. Unlike the before period, in the after period, level 2 conflicts were not observed. At all the sites, serious conflicts of levels 3-4 did not occur. Moreover, in the after period, no conflicts between PTWs and pedestrians were observed on the study sections.

Table 6 presents a summary of findings on the same issues for travel areas close to intersections (based on junction cameras). The findings show that under flowing/slow traffic conditions, in both periods, most PTWs (e.g. 61-83\% in the after period) did not change traffic lanes. In the after period compared to before, an increase in keeping lanes by PTWs was noted at most sites, while in two cases, the increase was significant. Under traffic congestion, in the after period, at most sites over half of PTWs (52-64\%) did not change the lanes, while comparing between the periods, mixed changes were observed in this behavior. At most sites, under congestion, most PTWs filtered between vehicles in order to move ahead. However, at intersection J81, there was a decline in the percent of filtering PTWs in the after compared to before period.
In the after period, near intersections, under flowing traffic, almost no conflicts were observed between PTWs and other vehicles (see Table 6); all the cases were of levels 1-2, i.e. interactions between road users without collision risk. One "near-miss" case (level 3) was observed between a PTW and a pedestrian (at J151), where the pedestrian crossed at a red light. Under congestion, at all intersections in the study, no conflicts were observed between PTWs and other vehicles or pedestrians.

It can be added that according to mobile cameras' films taken by the PTWs passing through the routes, in both periods, no conflicts occurred between PTWs and other vehicles. Nonetheless, in the after period, the lane change behavior by PTWs did not decline. Similarly, in the analysis of samples which reflected behaviors on the bus lanes, both on the study sections and near intersections, no conflicts between PTW and buses were observed ${ }^{3}$.

In summary, the findings showed that when travelling through a road segment, most PTWs kept to their lanes, especially near intersections, but in the period of the new measure, a consistent improvement was not found in this

3 Details of theses samples are not presented here but we can note that in the after compared to before period, no significant changes were observed in bus travel conditions or conflict occurrences between buses and other vehicles (on the bus lanes). 
behavior. Under traffic congestion, most PTWs tended to filter ahead between standing vehicles, yet, signs of a decline were observed in this behavior under the new arrangement. In the after compared to before period, there was no significant difference in conflict occurrences between PTWs and other road users: the conflicts did not disappear, but they reflected the existence of interactions between PTWs and other vehicles and did not point to a rise in the risk.

As indicated in Sec.2, special attention in the study was devoted to the situations where a PTW appeared behind a bus stopping at a bus stop - see example in Figure 3. For a detailed examination of this issue, specific data samples were collected for the study sites with bus stops - Sites 2-4. The data revealed that such occurrences were common only at Sites 2 and 4; Table 7 provides a summary of findings at those sites. It should be noted that at Site 2, the bus stop was on the bus lane (no bay), while at Site 4 , the bus stop was in a bay near the bus lane.

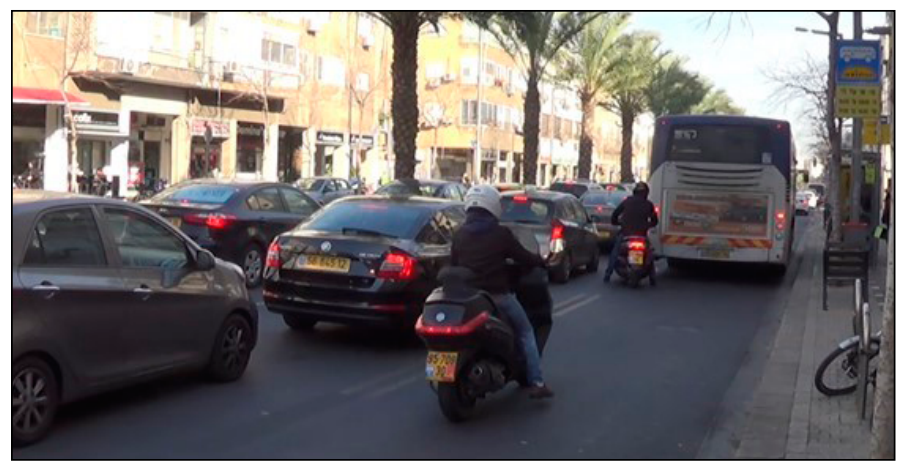

Figure 3. An example of PTW appearance behind a bus stopping at the bus stop.

In Table 7, one can notice that in the after period, in situations where a PTW appeared behind a bus stopping at the bus stop, at Site 2, in most cases the PTW changed the lane and continued travelling, while at Site 4, in half the cases, the PTW waited and did not change the lane. At both sites, if the PTW chose to continue travelling, it primarily moved between the bus lane and the adjacent lane. In the after period compared to before, in this behavior, no change was observed at Site 2, while at Site 4, a higher share of PTWs chose to wait and did not filter between the lanes. In addition, in the after period, in such situations, the prevalence of conflicts between PTWs and other vehicles, at Site 2, diminished. At both sites, all the conflicts observed were of low risk level: most of the cases were of level 1 ("precaution"), and a few cases of level 2 ("under control"). To summarize, after implementing the new measure, in this context, an increase in accident risk was not observed: the number of interactions between PTWs and other vehicles diminished or remained unchanged, where sufficient caution was undertaken by the parties involved in these incidents.

\subsection{Passing times through the routes}

Table 8-a presents a summary of passing times for buses, on the trial routes, based on the data derived from the bus company. The findings show that under the new measure, no increase in bus travel times was observed compared to the before period: on Route 1, in one direction, bus passing times have decreased; in other cases, the differences between bus travel times in both periods were insignificant.

Table 8-b shows the PTW passing times on the study routes, based on the data of mobile cameras of the PTW volunteers. It can be seen that in the period of the new arrangement compared to the before period, no change was observed in the PTW passing times on Route 1, in both travel directions, and on Route 2 in one direction, while in another direction on Route 2, an increase in the PTW travel time was found.

The additional examinations of passing times of the PTWs and buses based on the data collected from section cameras provided rather similar results: the after-before changes in the PTW passing times were inconsistent, indicating an increase at Sites 1, 2, 5, a decrease at Site 4 and no change at Site 3; as to bus travel times, in the after period compared to before, there was a decrease at Site 4 , an increase at Site 2 and no change at other sites.

Therefore, allowing a shared use of the bus lanes did not cause a consistent increase in bus travel times but also did not reduce PTW travel times, on the trial routes.

\begin{tabular}{|c|c|c|c|c|c|c|c|c|c|c|c|c|}
\hline \multirow[b]{2}{*}{$\underset{D}{\stackrel{\mathscr{D}}{*}}$} & \multicolumn{6}{|l|}{ Before } & \multicolumn{6}{|l|}{ After } \\
\hline & $\begin{array}{c}\text { No of } \\
\text { buses } \\
\text { stopped }\end{array}$ & $\begin{array}{l}\text { No of PTWs } \\
\text { appeared be- } \\
\text { hind stopped } \\
\text { buses }\end{array}$ & $\begin{array}{l}\text { PTWs } \\
\text { waited } \\
(\%)\end{array}$ & $\begin{array}{l}\text { PTW con- } \\
\text { flicts with } \\
\text { vehicles } \\
\text { (\%) }\end{array}$ & $\begin{array}{c}\text { No of } \\
\text { conflicts: } \\
\text { level } 1\end{array}$ & $\begin{array}{c}\text { No of } \\
\text { conflicts: } \\
\text { level } 2\end{array}$ & $\begin{array}{c}\text { No of } \\
\text { buses } \\
\text { stopped }\end{array}$ & $\begin{array}{l}\text { No of PTWs } \\
\text { appeared be- } \\
\text { hind stopped } \\
\text { buses }\end{array}$ & $\begin{array}{l}\text { PTWs } \\
\text { waited } \\
(\%)\end{array}$ & $\begin{array}{l}\text { PTW con- } \\
\text { flicts with } \\
\text { vehicles } \\
\text { (\%) }\end{array}$ & $\begin{array}{c}\text { No of } \\
\text { conflicts: } \\
\text { level } 1\end{array}$ & $\begin{array}{c}\text { No of } \\
\text { conflicts: } \\
\text { level } 2\end{array}$ \\
\hline 2 & 249 & 63 & 14.3 & 92.1 & 56 & 2 & 202 & 59 & 6.8 & $74.6^{\circ}$ & 43 & 1 \\
\hline 4 & 479 & 43 & 32.6 & 0 & -- & -- & 590 & 130 & $50.0^{*}$ & 5.4 & 6 & 1 \\
\hline
\end{tabular}

Note: $\mathrm{p}<0.05$ in after-before comparisons.

Table 7. PTW behaviors near buses which stopped at the bus stops (section cameras).

\begin{tabular}{|c|c|c|c|c|c|}
\hline a - Passing times of buses, min:sec & Before: average & sd & After: average & sd & Difference: after vs before period \\
\hline Route 1 , to north & $12: 24$ & $01: 39$ & $11: 47$ & 01:05 & no change, $\mathrm{p}=0.101$ \\
\hline Route 1 , to south & $13: 13$ & $02: 21$ & $11: 28$ & $02: 20$ & decrease, $\mathrm{p}<0.05$ \\
\hline Route 2 , to north & $06: 22$ & 01:18 & $06: 38$ & $01: 14$ & no change, $\mathrm{p}=0.45$ \\
\hline Route 2 , to south & $07: 58$ & 03:11 & 08:00 & $02: 31$ & no change, $\mathrm{p}=0.96$ \\
\hline b - Passing times of PTWs, min:sec & Before: average & sd & After: average & sd & Difference: after vs before period \\
\hline Route 1 , to north & $5: 44$ & $0: 59$ & $5: 50$ & $0: 44$ & no change, $\mathrm{p}=0.87$ \\
\hline Route 1 , to south & $6: 59$ & $1: 30$ & $6: 48$ & $0: 07$ & no change, $\mathrm{p}=0.86$ \\
\hline Route 2 , to north & $3: 26$ & $0: 28$ & $3: 20$ & $0: 18$ & no change, $\mathrm{p}=0.66$ \\
\hline Route 2 , to south & $3: 36$ & $0: 52$ & $5: 02$ & $0: 47$ & increase, $\mathrm{p}<0.01$ \\
\hline
\end{tabular}

Table 8. Passing times through the study routes, in before and after periods. 


\subsection{Accident rates}

Table 9 shows accident numbers observed and monthly accident rates estimated for the study routes, in before and after periods. On both routes, mixed accident changes can be indicated in the after compared to the before period, but no change was statistically significant. The lack of significance can be partly related to the short after period and relatively low accident counts observed on the study routes. Concerning PTW-involved accidents, signs of a decrease can be noted on road sections of both routes, in the after period, with no serious accidents observed both on sections and at the intersections. Such changes are in line with some previous studies (TfL, 2008; York et al., 2008), which reported on lower accident numbers following the measure's implementation, in selected areas.

A meta-analysis of changes in monthly accidents rates, across the four estimates (in Table 9) indicated an increasing trend in total injury accidents (a mean effect of $+25 \%$ ) and no change (a mean effect of $+1 \%$ ) in total accidents with PTWs. Furthermore, to exclude a seasonal effect, a complementary analysis of accident numbers was performed, with matched time periods: the "after" period of March-August 2016, and a "before" period of the same months in the previous years, 2014 and 2015 (Appendix A). Similar to the initial results, in this analysis, mixed trends were observed both in total and PTW-involved accidents, during the trial as opposed to the before period, with no significant change.

\section{DISCUSSION AND CONCLUSIONS}

Being aware of the growing use of motorcycles as a mobility means in dense urban areas and seeking ways for improving PTW riders' safety, a trial allowing a shared use of bus lanes by PTWs was undertaken in Tel-Aviv, Israel. This study examined the mobility and safety impacts of this measure, based on the analysis of changes in PTW behaviors, while passing through the trial routes, and accident changes, in the period of the measure's implementation compared to before periods. A wide range of behavior indicators was collected and analyzed by the study, based on the experience of previous research on the topic that was mainly conducted in the United Kingdom (TfL, 2008; York et al, 2008; 2010; 2011).
Furthermore, the behavior indicators in the study were defined aiming to examine a comprehensive list of expectations which are associated with the measure in the international literature (York et al., 2008; 2010; 2011; 2-Be-Safe, 2012; eSUM, 2012; IHE, 2015).

The main study findings regarding the changes in traffic and behaviors indicators on the study routes, in the after compared to before period, and relatively to expectations from the measure in the literature, can be suggested as follows:

- As expected, the new traffic arrangement caused an increase in bus lane usage by motorcycles, in Tel-Aviv. In particular, the share of PTWs in the bus lane traffic increased by $2-3 \%$. The rate of selecting bus lanes by PTWs (out of the total PTWs observed) increased by $4-5 \%$ in the conditions of moving traffic and by $6 \%-8 \%$ in traffic congestion. The extent of increase in the PTW traffic on the bus lanes, following the measure's introduction, in the current study was close to that reported by British studies, while the shares of PTWs using bus lanes was lower in Tel-Aviv than in London (York et al., 2008; 2010).

- At the same time, PTWs in Tel-Aviv continued to be observed in other traffic lanes, which was contrary to expectations from the literature but can be associated with a general growth in the PTW volumes on the study routes, in the after period.

- Concerning other PTW behaviors, the study findings showed that when travelling through a road segment, most PTWs kept to their lane, especially near intersections, but in the period of the new measure, a consistent change was not found in this behavior. In traffic congestion, most PTWs tended to filter ahead between standing vehicles, yet, signs of a decline were observed in this behavior under the new arrangement. In general, a consistent improvement in these PTW behaviors, which could be associated with a lower accident risk, was not observed in the current study.

- For all traffic situations examined by the study: travelling on the street segments, near intersections, in the areas of bus stops - the measure did not bring about an essential change in conflict occurrences between PTWs and other

\begin{tabular}{|c|c|c|c|c|c|c|c|c|c|c|c|c|}
\hline \multirow[b]{2}{*}{$\begin{array}{l}\text { Accident } \\
\text { types: }\end{array}$} & \multicolumn{6}{|c|}{ On sections } & \multicolumn{6}{|c|}{ At junctions } \\
\hline & $\begin{array}{l}\text { Total } \\
\text { with } \\
\text { injury }\end{array}$ & Serious & $\begin{array}{l}\text { Total } \\
\text { with } \\
\text { buses }\end{array}$ & $\begin{array}{l}\text { Serious } \\
\text { with } \\
\text { buses }\end{array}$ & $\begin{array}{l}\text { Total } \\
\text { with } \\
\text { PTWs }\end{array}$ & $\begin{array}{l}\text { Serious } \\
\text { with } \\
\text { PTWs }\end{array}$ & $\begin{array}{l}\text { Total } \\
\text { with } \\
\text { injury }\end{array}$ & Serious & $\begin{array}{l}\text { Total } \\
\text { with } \\
\text { buses }\end{array}$ & $\begin{array}{l}\text { Serious } \\
\text { with } \\
\text { buses }\end{array}$ & $\begin{array}{l}\text { Total } \\
\text { with } \\
\text { PTWs }\end{array}$ & $\begin{array}{l}\text { Serious } \\
\text { with } \\
\text { PTWs }\end{array}$ \\
\hline \multicolumn{13}{|c|}{ Route 1: Accident numbers } \\
\hline before & 23 & 6 & 3 & 2 & 10 & 4 & 29 & 4 & 1 & 1 & 8 & 1 \\
\hline after & 10 & 3 & 2 & 1 & 2 & 0 & 8 & 0 & 1 & 0 & 4 & 0 \\
\hline \multicolumn{13}{|c|}{ Route 1: Monthly accident rates } \\
\hline before & 0.92 & 0.24 & 0.12 & 0.08 & 0.40 & 0.16 & 1.16 & 0.16 & 0.04 & 0.04 & 0.32 & 0.04 \\
\hline after & 1.43 & 0.43 & 0.29 & 0.14 & 0.29 & 0.0 & 1.14 & 0.0 & 0.14 & 0.0 & 0.57 & 0.0 \\
\hline p-value ${ }^{*}$ & 0.24 & 0.41 & 0.34 & 0.64 & 0.66 & -- & 0.97 & -- & 0.37 & -- & 0.34 & -- \\
\hline \multicolumn{13}{|c|}{ Route 2: Accident numbers } \\
\hline before & 27 & 0 & 2 & 0 & 8 & 0 & 56 & 6 & 0 & 0 & 15 & 2 \\
\hline after & 5 & 0 & 0 & 0 & 1 & 0 & 23 & 1 & 0 & 0 & 4 & 0 \\
\hline \multicolumn{13}{|c|}{ Route 2: Monthly accident rates } \\
\hline before & 1.08 & 0.0 & 0.08 & 0.0 & 0.32 & 0.0 & 2.24 & 0.24 & 0.0 & 0.0 & 0.60 & 0.08 \\
\hline after & 0.71 & 0.0 & 0.0 & 0.0 & 0.14 & 0.0 & 3.29 & 0.14 & 0.0 & 0.0 & 0.57 & 0.0 \\
\hline $\mathrm{p}_{\text {-value }}^{*}$ & 0.40 & -- & -- & -- & 0.45 & -- & 0.12 & 0.63 & -- & -- & 0.93 & -- \\
\hline
\end{tabular}

Notes: "before: 1/2014-1/2016; after: 2-8/2016. "in before-after comparisons. No fatal accidents were observed.

Table 9. Accident numbers and monthly accident rates, in before and after periods", on the study routes 
road users. The conflicts did not disappear, but they reflected the existence of interactions between PTWs and other vehicles and did not point to a rise in the risk. Despite the initial concerns, the amount and the severity of conflicts between PTWs and other vehicles near the bus stops did not increase. In general, the observations showed that the new arrangement was not associated with a worsening of traffic safety on the bus lanes.

- Due to relatively small changes in the use of bus lanes by PTWs during the trial, the passing times of buses and PTWs through the pre-defined street sections did not change significantly. The measure did not bring about a consistent decrease in the PTW travel times along the study routes, but neither hinder the bus travel times, i.e. both positive and negative expectations from the measure were not realized in the current study.

Finally, mixed trends were observed in accident numbers on the trial routes, with no significant change, while signs of a decrease were indicated in some PTW-involved accidents. These findings were in line with previous research which usually reported insignificant accident changes following the measure's introduction and, sometimes, a decline in PTW accidents (TfL, 2004; 2008; York et al., 2008; 2011; 2-Be-Safe, 2012).

The limitations of the current study lie in the limited number of routes where the measure was announced and in the short after period, which led to small data samples in some cases (e.g. accident numbers) and may be related to the lack of significance in findings. It seems that traffic congestion conditions were not sufficiently covered by the study sites. To examine interactions between PTWs and other road users, on the bus lanes, longer observation periods are needed (than one-day observations applied in the current study). Furthermore, recognizing the variety of values of behavior indicators that were observed at the study sites, more detailed examinations of the characteristics of road layout, urban environment, frequency of bus traffic, etc., while considering the impacts of the measure, would be useful in the future research.

The definition of conflict adopted in the current study followed the experience of previous research on the topic (Ewing \& Dumbaugh, 2009; York et al., 2010), but was based on a visual interpretation by an observer and thus may be criticized. Due to low numbers of conflicts observed in this study, a formal conflict analysis technique was not applied, but all the cases were double-checked by the study team. Future research on the topic should include a wider number of sites and longer time periods, with preferably automated video-analyses (e.g. Laureshyn et al., 2010). The analyses of large samples of interactions between PTWs and other road users by means of conflict analysis techniques, will be useful for better understanding of conflict occurrences under the shared use of bus lanes by PTWs and buses, as well as for the development of additional measures for improving PTW riders' safety.

Summarizing the study findings, it can be concluded that the trial in Tel-Aviv displayed mixed results. The findings showed that allowing PTW travels on the bus lanes was associated with slight improvements in the PTW mobility, without impairing bus travel times or detrimental changes in safety of the road users. PTW behaviors under the new arrangement were rather similar to those observed in the period before implementing the measure. The absence of substantial behavior changes during the trial might indicate that the new measure actually "regulated" the situation that was previously present in traffic. The current study supports the conclusion of the European 2-Be-Safe (2012) project which considered PTW travelling in bus lanes as a measure for mainly improving
PTW mobility. More large-scale studies are needed to investigate whether this measure may contribute to improving PTW safety, as suggested by eSUM (2012).

\section{Acknowledgements}

This study was commissioned by the Ministry of Transport and Road Safety in Israel, Chief Scientist's Unit.

\section{REFERENCES}

Araujo, M., Illanes, E., Chapman, E. \& Rodrigues, E. (2016). Effectiveness of interventions to prevent motorcycle injuries: systematic review of the literature. International Journal of Injury Control and Safety Promotion, doi: 10.1080/17457300.2016.1224901

Breene, J. (2018). Preparatory work for an EU road safety strategy 2020-2030. J. Breene Consulting, SWOV and Loughborough University. European Commission.

CBS (2017). Motor vehicles 2016. Publication No 1618. Central Bureau of Statistics, the State of Israel, Jerusalem.

CBS (2019). Road accidents with casualties 2018: General summaries. Publication No 1773. Central Bureau of Statistics, the State of Israel, Jerusalem.

eSUM (2012). PTWs in bus lanes. BP2 001. European Safer Urban Motorcycling (eSUM). https://ec.europa.eu/ transport/road_safety/sites/roadsafety/files/pdf/projects sources/bp2-highway features and policy-en.pdf (Accessed on 23.1.16)

Ewing, R., and Dumbaugh, E. (2009). The built environment and traffic safety: A review of empirical evidence. Journal of Planning Literature, 23(4), 347-367.

Fredriksson, R., Sui, B. (2015). Fatal powered two-wheeler (PTW) crashes in Germany - an in-depth study of the events, injuries and injury sources. In Proceedings of Conference IRCOBI, Lion, France.

Griffith, M. S. (1999). Statistical Analysis Techniques. Ch. 4 in: Statistical Evaluation in Traffic Safety Studies. Institute of Transportation Engineers, Publication No IR-097, Washington, DC.

Haworth, N. (2012). Powered two wheelers in changing world: challenges and opportunities. Accident Analysis and Prevention, 44(1), 12-18.

IHE (2015). Guidelines for motorcycling, road design $\mathcal{E}$ traffic engineering. Institute of Highways Engineers, United Kingdon. http://www.motorcycleguidelines.org. uk/wp-content/uploads/2013/08/IHE-Guidelines-forMotorcycling-Road-Design-Traffic-Engineering.pdf (Accessed on 24.7.15).

IMMA (2014). The shared road to safety. A global approach for safer motorcycling. International Motorcycle Manufactures Association.

ITF (2015). Improving safety for motorcycles, scooter and moped riders. International Transport Forum, OECD Publishing, Paris. http://dx.doi.org/10.1787/9789282107942-en

Jekel, J. F., Katz, D. L., Elmore, J. G., and Wild, D. (2007). Epidemiology, biostatistics and preventive medicine. Elsevier Health Sciences.

Keall, M., Newstead, S. (2012). Analysis of factors that increase motorcycle rider risk compared to car driver risk. Accident Analysis and Prevention, 49, 23-29.

Laureshyn, A., Svensson, A., \& Hyden, C. (2010). Evaluation of traffic safety, based on micro-level behavioural data: Theoretical framework and first implementation. Accident Analysis and Prevention, 42, 1637-1646.

Rogers, N. (2008). Trends in motorcycles fleet worldwide. Presentation to Joint OECD/ITF Transport Research Committee Workshop on Motorcycling Safety. http://www. internationaltransportforum.org/jtrc/safety/Lillehammer2008/ Lillehammer08Rogers.pdf. 
RSA (2019). A decade of road safety in Israel 2008-2018. Road Safety Authority, Jerusalem.

TfL (2004). Powered two-wheelers in bus lanes: progress on experiments. 18-month Review Report. Transport for London, London.

TfL (2008). P2Ws in bus lanes study. Main Report. Transport for London, London.

2-Be-Safe (2012). 2-Wheeler Behaviour and Safety. Powered TwoWheelers Safety Measures. Guidelines, Recommendations and Research Priorities. 7th Framework Programme of the European Community.

Van Eslande, P., Elvik, R. (2012). Powered two-wheelers within the traffic system. Accident Analysis and Prevention, 49, 1-4.
Vlahogianni, E., Yannis, G., Golias, J. (2012). Overview of critical risk factors in power-two-wheeler safety. Accident Analysis and Prevention, 49, 12-22.

York, I., Webster, D., Sakamoto, K. (2008). Impacts of motorcycles in Westminster Bus Lanes. Published Project Report PPR365. Transport Research Laboratory, Crowthorne, UK.

York, I., Ball, S., Anjum, O., Webster, D. (2010). Assessment of TfL's experimental scheme to allow motorcycles onto with-flow bus lanes on the TLRN. Final Project Report PPR495. Transport Research Laboratory, Crowthorne, UK.

York, I., Ball, S., Hopkin, J. (2011). Motorcycles in Bus Lanes Monitoring of the Second TfL trial. Report CPR1224. Transport Research Laboratory, Crowthorne, UK.

\section{APPENDIX A. COMPLEMENTARY ANALYSIS OF ACCIDENT NUMBERS, ON THE STUDY ROUTES,}

WITH MATCHED BEFORE AND AFTER PERIODS\#.

\begin{tabular}{|c|c|c|c|c|c|c|}
\hline & On sections & & & At junctions & & \\
\hline Accident types: & Total with injury & Serious & Total with PTWs & Total with injury & Serious & Total with PTWs \\
\hline \multicolumn{7}{|c|}{ Route 1: Accident numbers } \\
\hline before & 9 & 4 & 4 & 12 & 2 & 3 \\
\hline after & 7 & 1 & 2 & 7 & 0 & 4 \\
\hline \multicolumn{7}{|c|}{ Route 1: Monthly accident rates } \\
\hline before & 0.75 & 0.33 & 0.33 & 1.00 & 0.17 & 0.25 \\
\hline after & 1.17 & 0.17 & 0.33 & 1.17 & 0.0 & 0.67 \\
\hline p-value* & 0.38 & 0.54 & 1.00 & 0.75 & -- & 0.20 \\
\hline \multicolumn{7}{|c|}{ Route 2: Accident numbers } \\
\hline before & 11 & 0 & 4 & 20 & 4 & 5 \\
\hline after & 4 & 0 & 1 & 12 & 1 & 2 \\
\hline \multicolumn{7}{|c|}{ Route 2: Monthly accident rates } \\
\hline before & 0.92 & 0.0 & 0.33 & 1.67 & 0.33 & 0.42 \\
\hline after & 0.67 & 0.0 & 0.17 & 2.00 & 0.17 & 0.33 \\
\hline p-value ${ }^{*}$ & 0.59 & -- & 0.54 & 0.62 & 0.54 & 0.79 \\
\hline
\end{tabular}

Notes: "before: 3-8/2014 and 3-8/2015; after: 3-8/2016. "in before-after comparisons. 